\title{
Interfacial microstructure and mechanical properties of Ti-6Al-4V/Al7050 joints fabricated using the insert molding method
}

\author{
Hong-xiang $\mathrm{Li}^{1)}$, Xin-yu $\mathrm{Ni}^{1)}$, Zan-bing He ${ }^{1)}$,Kang-ning Zhao ${ }^{1)}$, Qiang D ${ }^{2)}$, Ji-shan Zhang ${ }^{1)}$, and \\ Lin-zhong Zhuang ${ }^{1,3)}$ \\ 1) State Key Laboratory for Advanced Metals and Materials, University of Science and Technology Beijing, Beijing 100083, China \\ 2) SINTEF Materials and Chemistry, Pb. 124 Blindern, NO-0314 Oslo, Norway \\ 3) IJmuiden Technology Centre, Tata Steel Research \& Development, 1970 CA IJmuiden, The Netherlands \\ (Received: 31 March 2017; revised: 1 August 2017; accepted: 3 August 2017)
}

\begin{abstract}
Ti-6Al-4V/Al7050 joints were fabricated by a method of insert molding and corresponding interfacial microstructure and mechanical properties were investigated. The interfacial thickness was sensitive to holding temperature during the first stage, and a good metallurgical bonding interface with a thickness of about $90 \mu \mathrm{m}$ can be obtained at $750^{\circ} \mathrm{C}$. X-ray diffraction, transmission electron microscopy, and thermodynamic analyses showed that the interface mainly contained intermetallic compound $\mathrm{TiAl}_{3}$ and $\mathrm{Al}$ matrix. The joints featured good mechanical properties, i.e., shear strength of $154 \mathrm{MPa}$, tensile strength of $215 \mathrm{MPa}$, and compressive strength of $283 \mathrm{MPa}$, which are superior to those of joints fabricated by other methods. Coherent boundaries between $\mathrm{Al} / \mathrm{TiAl}_{3}$ and $\mathrm{TiAl}_{3} / \mathrm{Ti}$ were confirmed to contribute to outstanding interfacial mechanical properties and also explained constant fracture occurrence in the Al matrix. Follow-up studies should focus on improving mechanical properties of the $\mathrm{Al}$ matrix by deformation and heat treatment.
\end{abstract}

Keywords: interfacial microstructure; interfacial bonding mechanism; mechanical properties; insert molding method; coherent boundaries; Ti/Al joints

\section{Introduction}

Given the low density, high specific strength, excellent corrosion resistance, notable impact toughness, and significant thermal stability, titanium alloys are widely used in vehicle, aerospace, chemistry, and defense industries. However, unavoidable shortcomings of titanium alloys, such as high production cost, low thermal conductivity, and low shear strength, constrain their widespread applications [1]. Aluminum alloys, as primary structural materials for commercial and military applications, are known for their excellent mechanical properties, easy to design, and mature manufacturing and inspection techniques. However, these materials also face other challenges, such as low hardness and wear resistance, low tensile strength at high temperature, and high linear expansion coefficient [2]. To overcome disadvantages of Ti alloys and $\mathrm{Al}$ alloys and to utilize their respective advantages, Ti/Al bimetallic joints have attracted more atten- tions in recent years [3-12]. For these two alloys, significant differences in physical properties, such as melting point and heat conductivity, make conventional preparation techniques unsuitable for fabricating Ti/Al joints. Novel methods, such as accumulative roll-bonding [3-5], laser welding-brazing [6-7], friction stir welding [8-9], powder metallurgy [10-11], and explosive cladding [12], were attempted. Despite these efforts, problems still exist with these fabrication methods: (i) poor interfacial bonding strength, (ii) complex processing procedures, and (iii) limited product sizes for industrial application.

Recently, a study of Ti/Al-7Si-0.3Mg joints prepared by a method of insert molding exhibited promising industrial application prospects due to low production cost, low energy consumption, simple production procedure, and high interfacial bonding strength [13-14]. The basic principle of this method is to immerse Ti insert into $\mathrm{Al}-7 \mathrm{Si}-0.3 \mathrm{Mg}$ melt at the optimized temperature. As a result, good metallurgical bonding 
can be attained by formation of an interfacial reaction layer. Owing to the aforementioned outstanding advantages, the authors also prepared $\mathrm{Ti} / \mathrm{Al}$ and $\mathrm{Ti}-6 \mathrm{Al}-4 \mathrm{~V} / \mathrm{Al}$ bimetallic joints using the same insert molding method [15-16]. Results showed that high interfacial shear strength can be obtained by tuning holding time at a certain temperature and optimizing the cooling method. Also, during shear fracture, cracks can initiate and propagate in Al matrix near the interface rather than in the interface reaction layer. Summarizing the above progress regarding preparation using the insert molding method, current studies mainly focus on bonding of pure $\mathrm{Al} /$ pure $\mathrm{Ti}$, pure $\mathrm{Ti} / \mathrm{Al}$ alloys, and pure Al/Ti alloys. So far, bonding of Ti alloys/Al alloys obtained using the same insert molding method is not performed though Ti-alloy/Al-alloy joints can exhibit more extensive industrial application prospects. Though high interfacial bonding strength can be attained, mechanism of interfacial strengthening from the insert molding method remains unknown. For these purposes, in this study, we selected two representative alloys, i.e., Ti-6Al-4V and AA7050 alloys, as two basic bonding metals and fabricated corresponding joints using the insert molding method. We also investigated interfacial microstructures and measured the mechanical properties of joints. Emphasis was placed on understanding mechanisms on interfacial bonding and strengthening of Ti-6Al-4V/AA7050 joints fabricated using the insert molding method.

\section{Experimental}

\subsection{Specimen preparation}

Joints were prepared by insert molding of commercial Al7050 (matrix) and Ti-6Al-4V (insert rods) alloys, whose compositions are illustrated in Table 1. The corresponding experimental set-up can be found in detail in Ref. [15]. During experiments, first, the aluminum alloy melt temperature was set to $790^{\circ} \mathrm{C}$. Ti-6 Al-4V rods were then inserted into the aluminum alloy melt. Such a high temperature was necessary to prevent the aluminum melt from solidifying around Ti-alloy rods upon their insertion into the A17050 melt and to avoid foundry defects. Second, to ensure integrity of the Ti-6Al-4V/A17050 interface, sufficient energy was provided for the interfacial diffusion reaction. Three temperatures $\left(770,750\right.$, and $\left.730^{\circ} \mathrm{C}\right)$ with the same holding time (40 $\mathrm{min}$ ) were selected to compare their influences on interfacial bonding behaviors. Third, to ensure secondary precipitation of the $\mathrm{TiAl}_{3}$ phase at the interface, the next process was set to $700^{\circ} \mathrm{C}$ for $10 \mathrm{~min}$. Then furnace cooling was performed until $670^{\circ} \mathrm{C}$ to reduce residual stress induced by difference in thermal expansion coefficients between Ti-6Al-4V and Al7050. Finally, to minimize the presence of a compact layer in which microcracks can be easily initiated due to the formation of brittle intermetallic compounds (reported in Ref. [15]), air cooling was implemented until room temperature.

Table 1. Chemical composition of $\mathrm{Al7050}$ and $\mathrm{Ti}-6 \mathrm{Al}-4 \mathrm{~V}$ alloys used to fabricate joints in the present study wt $\%$

\begin{tabular}{ccccccccccc}
\hline Material & $\mathrm{Si}$ & $\mathrm{Fe}$ & $\mathrm{Cu}$ & $\mathrm{Mg}$ & $\mathrm{Zn}$ & $\mathrm{Ca}$ & $\mathrm{V}$ & $\mathrm{Ti}$ & $\mathrm{Al}$ \\
\hline Al7050 & 0.04 & 0.07 & 2.49 & 2.42 & 6.3 & - & $0.30(\max )$ & 0.03 & $\mathrm{Balance}$ \\
Ti-6Al-4V & 0.09 & - & - & - & - & $0.30(\mathrm{max})$ & 4.42 & Balance & 6.13 \\
\hline
\end{tabular}

\subsection{Interfacial characterization}

After solidification, joints were sliced in a thickness of $5 \mathrm{~mm}$ by wire cut electrical discharge machining, and cross-sections of these slices were perpendicular to the rod axis. Surfaces of each specimen were then polished with $0.5 \mu \mathrm{m}$ diamond paste and utilized for interface microstructure characterization, chemical composition analysis by scanning electron microscopy (SEM), and electron probe micro-analysis (EPMA). Transmission electron microscopy (TEM), high-resolution TEM (HRTEM), and energy-dispersive X-ray spectroscopy (EDS) were performed to characterize interfacial microstructures and analyze phase constituents using a Tecnai G2 F30 microscope operated at $300 \mathrm{kV}$. TEM and HRTEM specimens were mechanically ground, polished, dimpled to $60 \mu \mathrm{m}$, and then thinned by ion milling using a Gatan precision ion polishing system (Gatan model 691.CS).

\subsection{Mechanical properties}

Interface shear strength was measured using classical push-out tests, as described in Ref [13]. A universal testing machine was used to conduct push-out tests. Interfacial shear strength $(\tau)$ can be calculated using the following equation $[13,15]$ :

$\tau=\frac{F_{\max }}{2 \pi r t}$

where $F_{\max }$ is the maximum load, $r$ refers to the radius of Ti-6Al-4V insert $(3 \mathrm{~mm})$, and $t$ denotes the specimen thickness $(5 \mathrm{~mm})$. Vickers hardness was measured across the interface layer under an indentation load of $2.94 \mathrm{~N}$ for 
$15 \mathrm{~s}$. The micro hardness value was evaluated by averaging three mediate values of five indentation measurements. Following the ASTM standard, plate-type tensile specimens with the gauge length of $25 \mathrm{~mm}$, gauge width of $6 \mathrm{~mm}$, and thickness of $3 \mathrm{~mm}$ were machined with axes perpendicular to the interface. Tensile tests were carried out on a universal testing machine, and the strain rate was $5 \times 10^{-5} \mathrm{~s}^{-1}$. A cylindrical cast sample of $10 \mathrm{~mm}$ in diameter and $20 \mathrm{~mm}$ long was cut for the uniaxial compression experiment at room temperature.

\section{Results}

\subsection{Interface characterization}

Fig. 1 shows the interfacial morphologies of samples at different holding temperatures $\left(770,750\right.$, and $\left.730^{\circ} \mathrm{C}\right)$. It also shows that at $730^{\circ} \mathrm{C}$, the interface thickness was $3 \mu \mathrm{m}$ owing to slow elemental diffusion. With increasing holding temperature, the interface thickness correspondingly increased. At $750^{\circ} \mathrm{C}$, a uniform thin interfacial layer with a thickness of $90 \mu \mathrm{m}$ was attained. However, at $770^{\circ} \mathrm{C}$, a thick interface with many shrinkage voids was observed. These voids were reported to exert detrimental effects on the me- chanical characteristics of bimetallic joints [13]. Thus, the interfacial morphologies of $\mathrm{Ti}-6 \mathrm{Al}-4 \mathrm{~V} / \mathrm{Al} 7050$ joints strongly depended on the holding temperature in the first stage, and good interfacial metallurgical bonding can be possibly attained by parameter optimization, as shown in Fig. 1(b). For deep analysis of interface microstructure, the interface layers of specimens at $750^{\circ} \mathrm{C}$ are enlarged in Fig. 1(d). A large number of irregular intermetallic particles were distributed in the black alloy matrix. Meanwhile, small amounts of white and gray phases were observed around intermetallic particles. To confirm the phase constituents at the interface shown in Fig. 1(d), EPMA analysis was performed. Corresponding results from spot scan and area scan are shown in Table 2 and Fig. 2, respectively. As shown in Fig. 2, Ti, Al, and $\mathrm{V}$ were more abundant in the newly formed intermetallic particles than those in the black alloy matrix. However, $\mathrm{Mg}, \mathrm{Zn}$, and $\mathrm{Cu}$ in the newly formed intermetallic particles were less than those in the black alloy matrix. Combined with the spot scan results in Table 2, irregular intermetallic particles and the black alloy matrix are the $\mathrm{TiAl}_{3}(\mathrm{~V})$ phase and the Al-alloy matrix, respectively. Similarly, white and gray particle phases were confirmed to be $\mathrm{S}\left(\mathrm{CuMgAl}_{2}\right) \mathrm{Zn}$ and $\mathrm{Al}_{3} \mathrm{Fe}$ phases, respectively. The interfacial
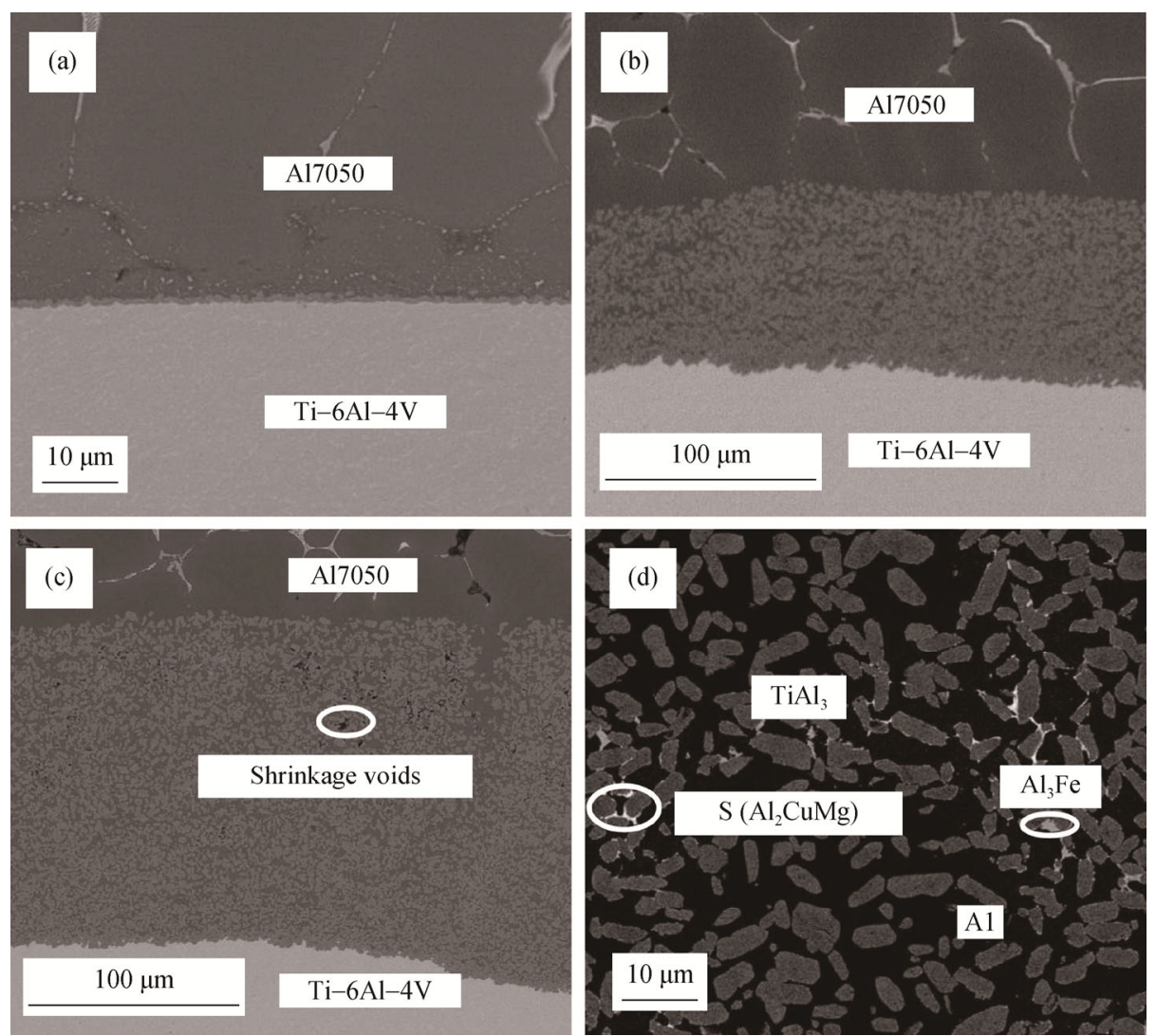

Fig. 1. Interface SEM images of the samples fabricated at different holding temperatures: (a) $730^{\circ} \mathrm{C},(\mathrm{b}) 7^{\circ} 0^{\circ} \mathrm{C}$, and (c) $770^{\circ} \mathrm{C}$; (d) enlarged SEM images of the Ti-6Al-4V/Al bonding interface at $750^{\circ} \mathrm{C}$ for studying the precipitation behavior of phases. 
Table 2. Spot scan results of irregular intermetallic compound particles, black alloy matrix, and white and light gray particle phases contained at the interface of Ti-6Al-4V/Al7050 joints fabricated by the insert molding method

\begin{tabular}{cccccccc}
\hline Phases & $\mathrm{Al}$ & $\mathrm{Cu}$ & $\mathrm{Ti}$ & $\mathrm{Mg}$ & $\mathrm{Zn}$ & $\mathrm{Fe}$ & $\mathrm{V}$ \\
\hline Intermetallic compound particles & 74.28 & 0.09 & 22.19 & 0.15 & 0.17 & 0 & 3.12 \\
Black alloy matrix & 93.31 & 0.78 & 2.11 & 1.32 & 2.33 & 0 & 0.15 \\
White particle phase & 46.82 & 14.17 & 0.0068 & 24.92 & 4.24 & 0 & 0 \\
Gray particle phase & 78.03 & 3.74 & 0.68 & 0 & 0 & 17.55 & 0 \\
\hline
\end{tabular}
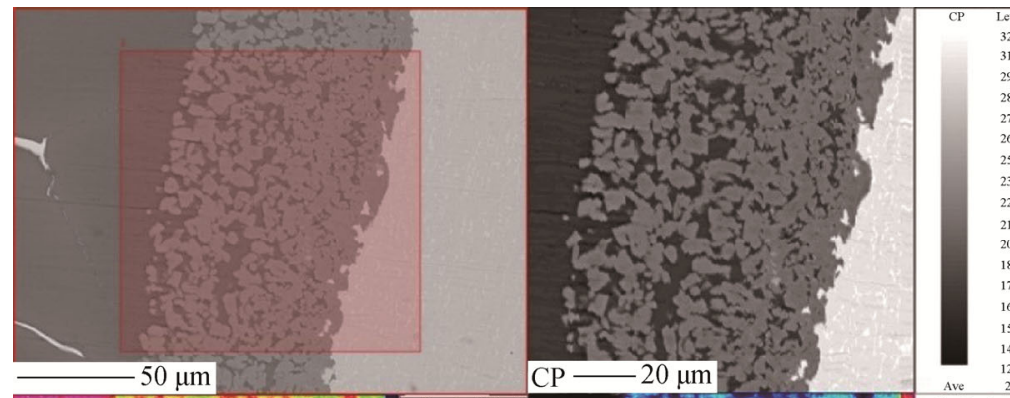

$\begin{array}{cc}\text { Lovel } & \text { Area1\% } \\ 3236 & 0.0 \\ 3114 & 0.8 \\ 2993 & 5.6 \\ 2871 & 9.2 \\ 2750 & 0.2 \\ 2628 & 0.1 \\ 2507 & 0.1 \\ 2385 & 0.2 \\ 2264 & 0.6 \\ 2142 & 18.0 \\ 2121 & 24.4 \\ 1899 & 6.0 \\ 1778 & 4.9 \\ 1656 & 19.4 \\ 1535 & 9.9 \\ 1413 & 0.5 \\ 1292 & 0.0 \\ 122 & 0.0\end{array}$
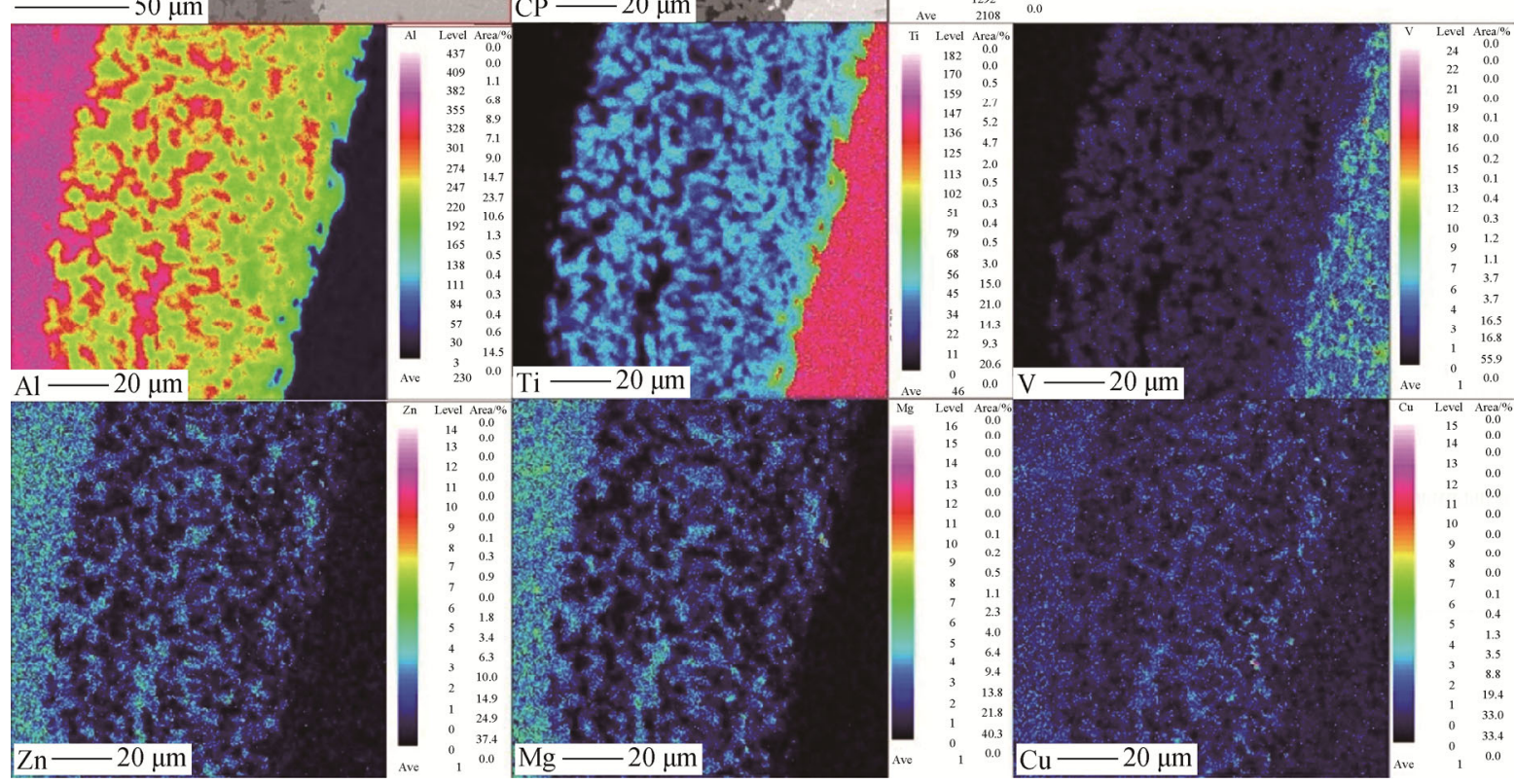

Fig. 2. Area scan spectrum maps of the Ti-6Al-4V/Al7050 reaction interface analyzed by EPMA.

energy for nucleation in the Al matrix is larger than that for nucleation in the interface of $\mathrm{Ti} / \mathrm{Al}$ intermetallic compounds. This observation explains why $\mathrm{S}\left(\mathrm{CuMgAl}_{2}\right) \mathrm{Zn}$ and $\mathrm{Al}_{3} \mathrm{Fe}$ phases were easily precipitated around $\mathrm{TiAl}_{3}(\mathrm{~V})$ particle phases rather than in the Al-alloy matrix. Besides the above four phases, a small number of tiny titanium particles were also observed at the interface around $\mathrm{Ti}-6 \mathrm{Al}-4 \mathrm{~V}$ alloy rods, as shown in Fig. 2.

Fig. 3 shows the XRD patterns at the interface. Peaks of $\mathrm{Al}$ and $\mathrm{TiAl}_{3}(\mathrm{~V})$ phases can be found in the same figure. Besides the two phases, smaller amounts of $\mathrm{Ti}$ and $\mathrm{S}\left(\mathrm{CuMgAl}_{2}\right) \mathrm{Zn}$ phases were also confirmed in the XRD patterns, in accordance with the aforementioned EDS analysis results shown in Table 2 . However, the $\mathrm{Al}_{3} \mathrm{Fe}$ phase cannot be observed from the XRD patterns, and this result is speculated to be related to its low concentration in the sample.

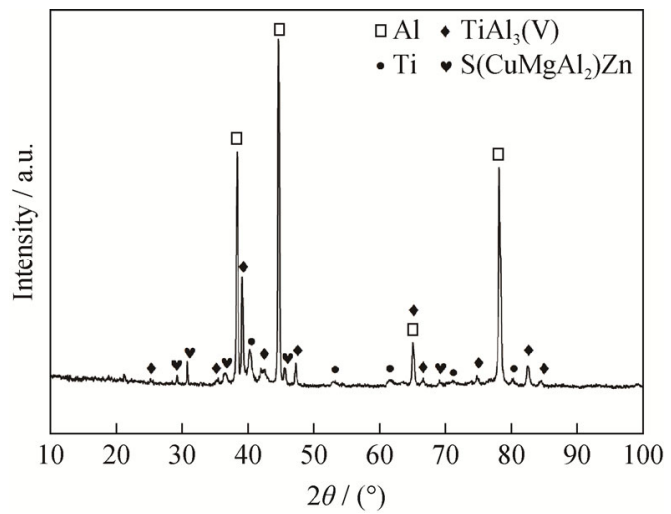

Fig. 3. XRD patterns of the $\mathrm{Ti}-6 \mathrm{Al}-4 \mathrm{~V} / \mathrm{Al}$ bonding interface at a holding temperature of $750^{\circ} \mathrm{C}$. 
We investigated the interfacial bonding behavior of pure $\mathrm{Al}$ and pure $\mathrm{Ti}$ joints fabricated by the insert molding method [15]. The interfacial bonding layer comprised $\mathrm{TiAl}_{3}$ and $\mathrm{TiAl}_{2}$ phases, with the $\mathrm{TiAl}_{2}$ phase existing around pure
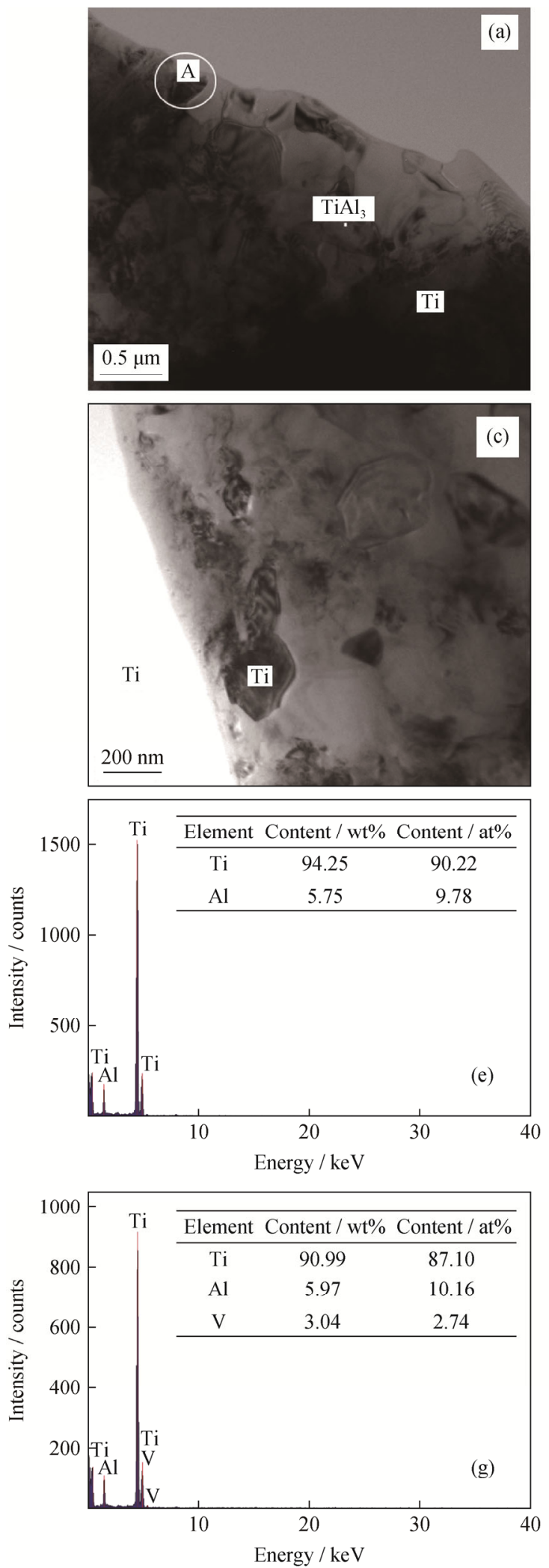

Ti rods. To investigate the interface phase constituents of Ti-6Al-4V/Al7050 joints, TEM analysis was carried out (Fig. 4) around Ti-6Al-4V insert rods. Results from selected area diffraction patterns (SADP) and EDS (shown in Fig. 4(d)
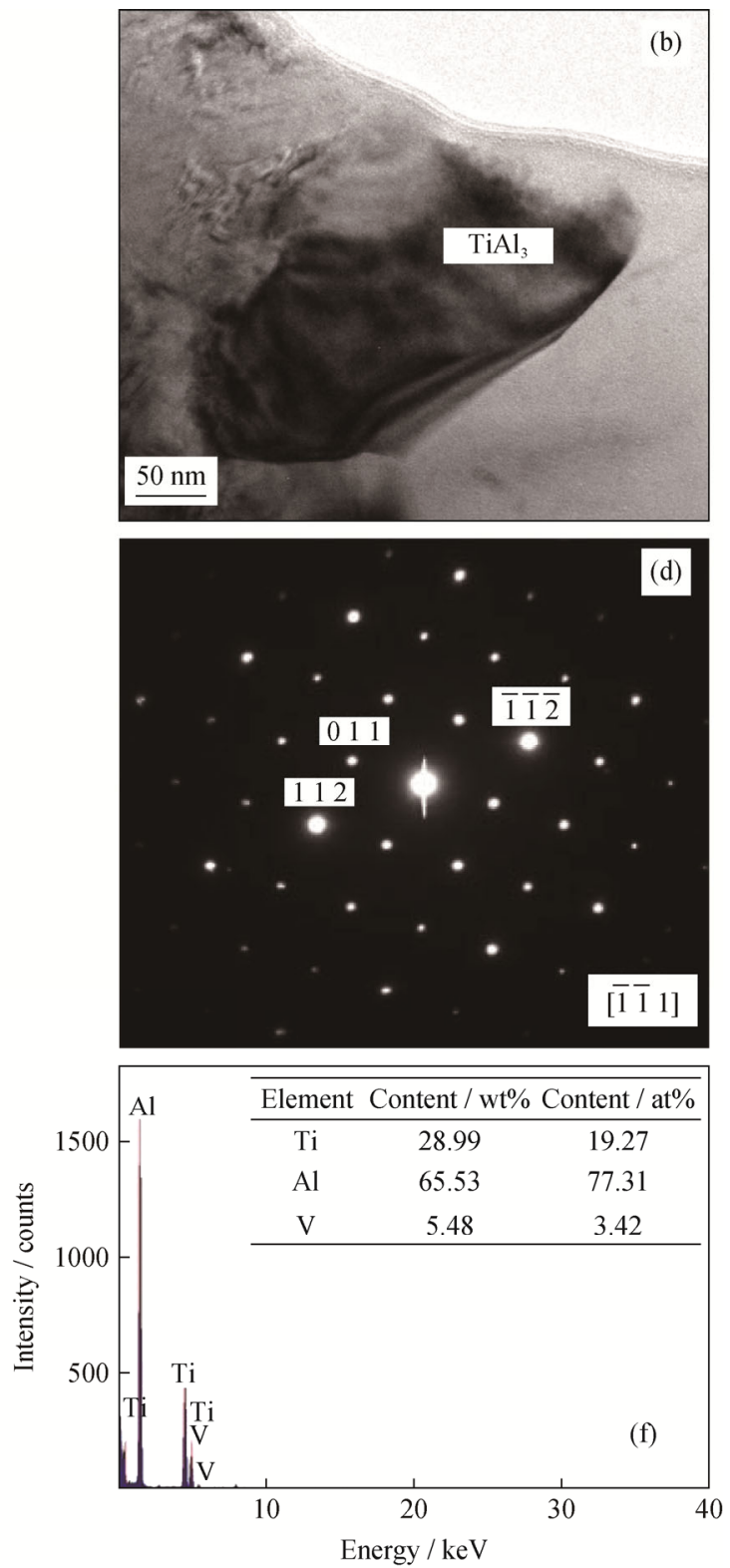

Fig. 4. TEM, SADP, and EDS analyses around Ti-6Al-4V insert rods: (a) TEM interface image approaching Ti insert rods; (b) enlarged TEM image of the $\mathrm{TiAl}_{3}$ phase from region $\mathrm{A}$ shown in (a); (c) TEM image of Ti particulates around Ti insert rods; (d) SADP for the $\mathrm{TiAl}_{3}$ phase shown in (b); (e) EDS analysis for the Ti region shown in (a); (f) EDS analysis for the $\mathrm{TiAl}_{3}$ region shown in (a); (g) EDS analysis for the Ti particulate shown in (c). 
and Fig. 4(f), respectively) confirmed that only the $\mathrm{TiAl}_{3}$ phase existed around Ti-alloy inserts, and this condition differs from the interfacial microstructures of previous pure $\mathrm{Ti} /$ pure $\mathrm{Al}$ joints. The cause of sole precipitation of $\mathrm{TiAl}_{3}$ phases (instead of other Ti-Al intermetallic compounds) around Ti-alloy rods will be discussed later. Tiny Ti particles (Fig. 4(g)) were confirmed around the Ti-alloy rod, indicating accordance with aforementioned EPMA and XRD analyses.

\subsection{Mechanical properties}

Ti-6Al-4V/Al7050 joints fabricated by the insert mold-
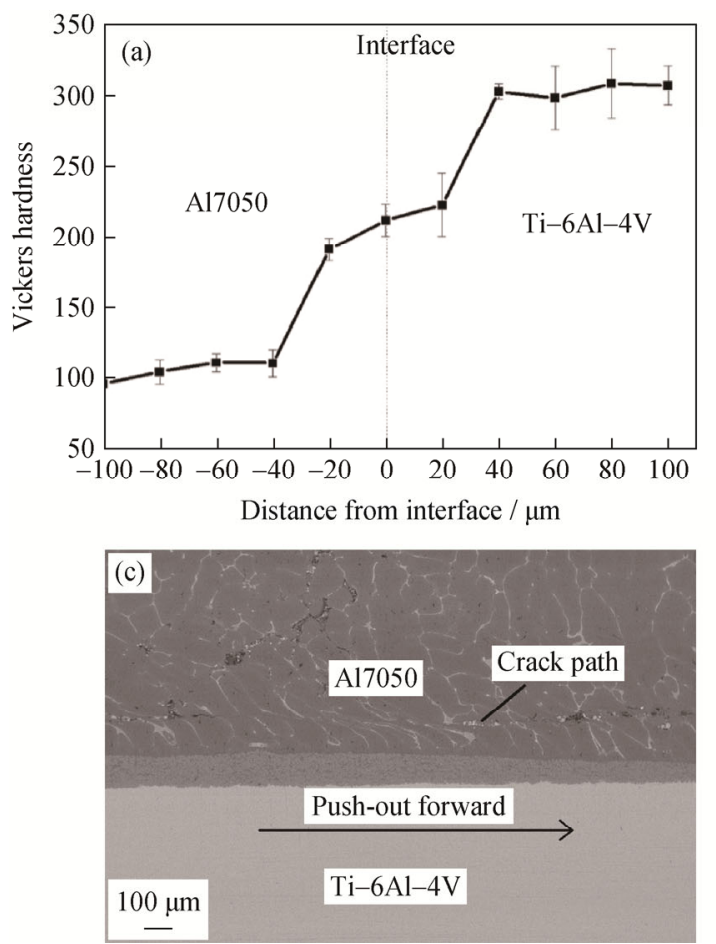

Fig. 5(b) shows the load-displacement curves of Ti-6Al4V/Al7050 specimens. Shear strength can be calculated from the push-out load and surface circumference of the insert according to Eq. (1) and as illustrated in Table 3. Table 3 also illustrates the shear strength values for some typical Ti-6Al4V/Al-alloy joints fabricated by different methods [17-25]. The shear strength value of Ti-6Al- 4V/Al7050 joints reached $154 \mathrm{MPa}$, which is superior to the values attained from other fabrication methods, such as transient liquid phase (TLP) bonding, indicating remarkable advantage in improving interfacial bonding strength by the current insert molding method. A push-out test of the Ti-6Al-4V/ Al7050 joint was also interrupted upon application of $80 \%$ of the maximum load value. Slices of this specimen were later cut with a diamond wire and polished to a finish better than ing method also exhibited outstanding mechanical performance. Fig. 5(a) shows the hardness measured across the interface. Hardness of the Ti-6Al-4V rod was measured to be HV 320, which is nearly three times that of the Al7050 matrix (HV 106). As the interface was mainly composed of $\mathrm{TiAl}_{3}$ (V) and the Al7050 alloy matrix, interface hardness reached a mediate value between those of titanium insert and aluminum matrix. As depicted in Fig. 5(a), intermetallic compounds formed on the insert side occupied a major portion of the interface, increasing the hardness value to approximately HV 210, which is higher than HV 180 on the $\mathrm{Al}$ matrix side.

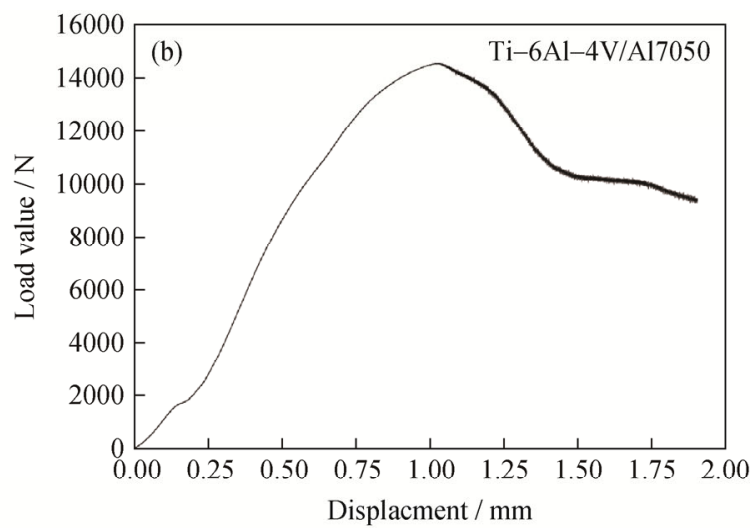

Fig. 5. Vickers hardness of the section in Ti-6Al-4V/Al7050 specimens fabricated by the insert molding method (a), typical Ti-6Al-4V/ Al7050 load-displacement curves obtained by push-out tests (b), and representative SEM image after the push-out test interrupted at $80 \%$ of the maximum load value exhibiting initiation of interfacial cracking (c).

$0.5 \mu \mathrm{m}$ to characterize the damage along the vertical section. Damage characterization performed by SEM (Fig. 5(c)) indicated that cracks can initiate at the bottom face of the specimen in the aluminum matrix rather than at the bonding interface, further confirming high interfacial bonding performance when insert molding was applied.

To further determine the interfacial mechanical performances of Ti-6Al-4V/Al7050 samples, traditional tensile and compressive tests were performed. Fig. 6 shows the macroscopic and microscopic scanning images of tensile and compressive fracture including stress-strain curves. Fig. 6(a) indicates that no significant differences (within experimental error) were observed in tensile strength between as-cast Al7050 (219 MPa) and Ti-6Al-4V/Al7050 samples fabricated by insert molding (215 MPa), confirming 
occurrence of fracture in the Al7050 alloy matrix. Fig. 6(c) displays a typical SEM fracture morphology of the Ti-6Al-4V/Al7050 bimetallic composite obtained after tensile tests. Some shallow dimples were detected on fracture surfaces, and some coarse iron-rich phases appeared in these shallow dimples, further confirming fracture of the as-cast A17050 alloy matrix. Based on the compression curve shown in Fig. 6(d), non-proportional compressive stress $\left(\sigma_{\mathrm{pc}}\right)$ of Ti-6Al-4V/A17050 reached $283 \mathrm{MPa}$. Fig. 6(e) shows lateral views of the macroscopic compressive fracture

Table 3. Comparisons of the mechanical performance of Ti-6Al-4V/Al alloy joints fabricated in the present study and those by other fabrication methods

\begin{tabular}{|c|c|c|c|c|}
\hline Material & Fabrication method & Maximum shear strength / MPa & Interface hardness, HV & Ref. \\
\hline Ti-6Al-4V/Al7050 & Insert molding & 154 & $180-210$ & This study \\
\hline Ti-6Al-4V/Al7075 & TLP bonding & 30 & $50-360$ & {$[17]$} \\
\hline Ti-6Al-4V/Al7075 & TLP bonding & 36 & $104-330$ & {$[18]$} \\
\hline Ti-6Al-4V/Al7075 & TLP bonding & 42.3 & $57-413$ & [19] \\
\hline Ti-6Al-4V/Al7075 & TLP bonding & 19 & $170-400$ & {$[20]$} \\
\hline Ti-6Al-4V/Al7075 & TLP bonding & 36 & 124 & {$[21]$} \\
\hline Ti-6Al-4V/Al1060 & Ultrasonic-assisted brazing in air & $68 \pm 2.3$ & - & {$[22]$} \\
\hline Ti-6Al-4V/Al2024 & TLP bonding & 37 & $118-153$ & {$[23]$} \\
\hline Ti-6Al-4V/Al2024 & Liquid state diffusion bonding & 36 & $75-344$ & {$[24]$} \\
\hline Ti-6Al-4V/Al2024 & TLP bonding & - & 139 & {$[25]$} \\
\hline
\end{tabular}
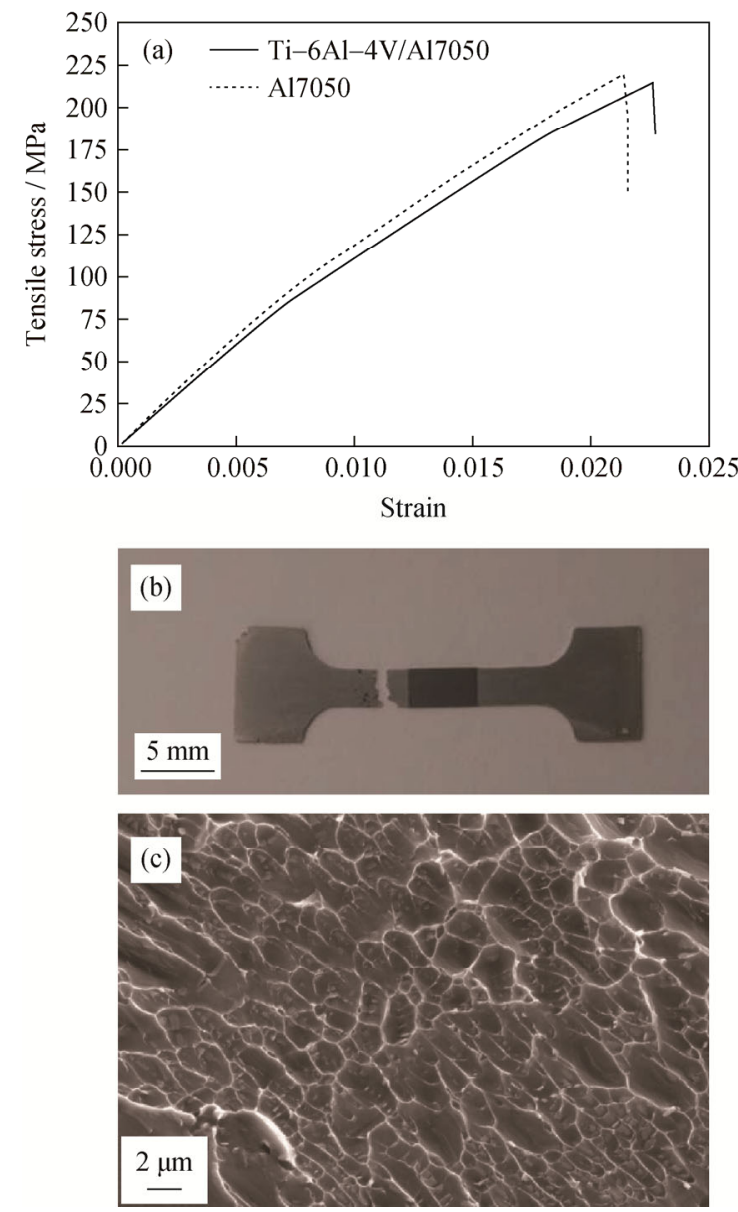
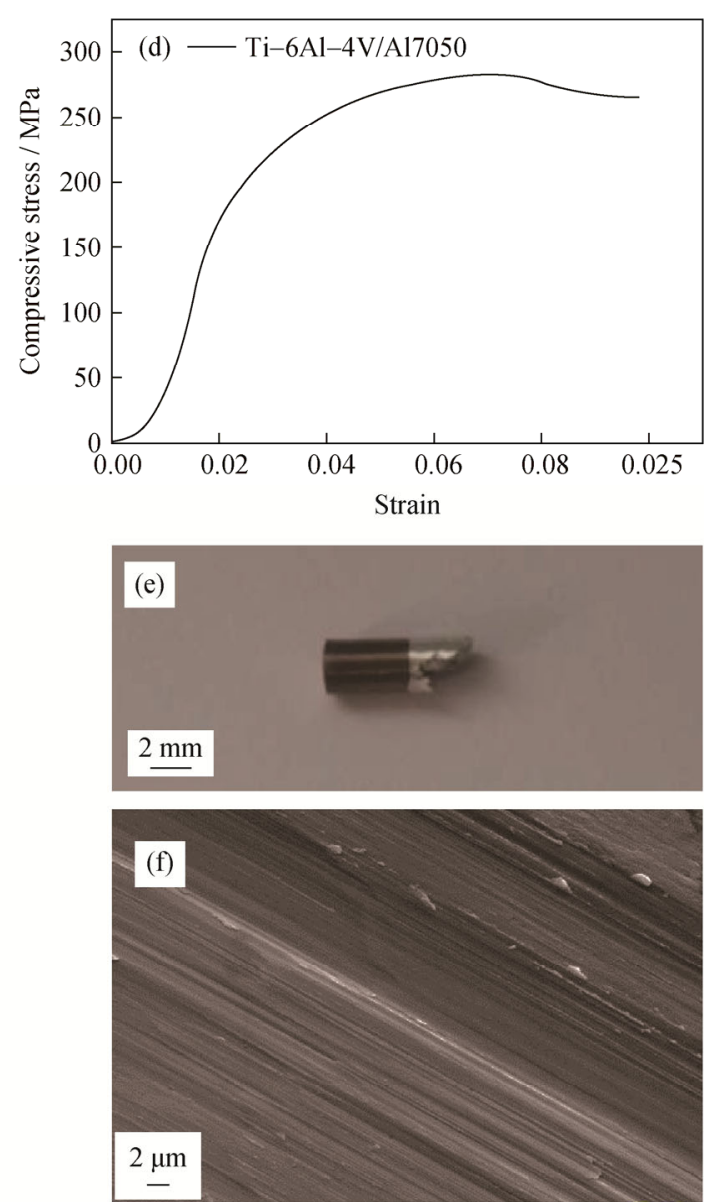

Fig. 6. Tensile and compressive test results of Ti-6Al-4V/Al7050 joints prepared by the insert molding method: (a) tensile stress-strain curves; (b) macroscopic tensile fracture morphology; (c) microscopic tensile fracture morphology; (d) compressive stress-strain curve; (e) lateral view of the macroscopic compressive fracture morphology; (f) microscopic compressive fracture surface morphology. 
morphology caused by the uniaxial compression experiment at room temperature. The $45^{\circ}$ compressive fracture plane can be observed throughout the aluminum matrix. Therefore, compressive fracture was mainly caused by shear stress, and the common failure mode was shear fracture. As a result, fibrous fracture surfaces can be observed in the SEM images of compressive samples (Fig. 6(f)). Different from tensile tests, the compression curve directly shows the yielding process. Based on the above results, interfacial bonding performance was enhanced by insert molding to prevent fracture at the interface bonding layer. Instead, fracture was initiated in the Al-alloy matrix. Tensile or compressive fracture characteristics are those of the A17050 matrix alloy. Chen et al. [7] reported that tensile strength of Al5A06/Ti$6 \mathrm{Al}-4 \mathrm{~V}$ prepared by the laser welding-brazing method can reach $292 \mathrm{MPa}$, which is higher than the current value observed. This result can be attributed to different treatment states of Al-alloy samples. Instead of the as-cast state of the Al7050 alloy used in this study, Chen et al. used Al-alloy matrices with different heat treatment states and as-rolled conditions. Instead of the tensile fracture observed in the Al alloy matrix in this study, tensile fracture from Chen's study was mainly located at the joint interface. Thus, mechanical performances of $\mathrm{Ti}-6 \mathrm{Al}-4 \mathrm{~V} / \mathrm{Al} 7050$ joints prepared in this study exhibit higher potential than those prepared by Chen et al. after further rolling and heat treatment of the Al-alloy matrix.

\section{Discussion}

\subsection{Interfacial bonding mechanism}

When temperature at the interface is above the melting point of aluminum alloy, both liquid and solid surfaces can experience separation of the surface oxidation layer and spreading of liquid aluminum due to capillary pressure [26-27]. Compared with the solubility of aluminum in titanium within the experimental temperature range, titanium in aluminum presents lower solubility [28], indicating that formation of intermetallic compounds at the interface is mainly related to the degree of diffusion of aluminum before complete solidification. As the lattice misfit between $\mathrm{TiAl}_{3}$ and $\mathrm{Ti}$ or $\mathrm{Al}$ is low, $\mathrm{TiAl}_{3}$ will preferentially nucleate and induce minimal increase in interfacial energy in Ti-Al compounds [29-30]. Within the experimental temperature range, sufficient $\mathrm{Al}$ atoms were dissolved into titanium inserts, guaranteeing the formation of $\mathrm{TiAl}_{3}$ phase until chemical equilibrium. As a result, the interface layer was mainly composed of $\mathrm{TiAl}_{3}$. To confirm this speculation, the thermodynamic behavior of Ti-Al intermetallic compounds were compared. Fig. 7 exhibits the free energy-temperature line of $\mathrm{Ti}-\mathrm{Al}$ intermetallic compounds and diffusion between $\mathrm{Ti}$ and $\mathrm{TiAl}_{3}$ from 630 to $900^{\circ} \mathrm{C}$ [30-31]. As shown in Fig. 7, free energies of $\mathrm{TiAl}_{3}$, $\mathrm{TiAl}_{2}$, and $\mathrm{Ti}_{2} \mathrm{Al}_{5}$ phases are lowest among Ti-Al intermetallic compounds at the experimental temperature. Though free energies of $\mathrm{TiAl}_{2}$ and $\mathrm{Ti}_{2} \mathrm{Al}_{5}$ are lower, intermetallic compound at the interface layer still mainly comprised $\mathrm{TiAl}_{3}$ phase. This result can be explained by the following reasons. First, phase-transition temperature of $\mathrm{Ti}_{2} \mathrm{Al}_{5}$ is beyond the experimental temperature, as observed from the Ti-Al binary phase diagram [32]. Second, during the formation of $\mathrm{Ti}_{2} \mathrm{Al}_{5}$ and $\mathrm{TiAl}_{2}$ phases, TiAl often acts as the intermediate phase $[29,32]$. TiAl and $\mathrm{Ti}_{3} \mathrm{Al}$ phases can only be formed in extreme absence of aluminum atoms near the titanium insert (Figs. 7(b)-7(c)). However, in this study, adequate aluminum atoms were supplied to participate in interface reactions during casting. Therefore, the TiAl phase was not easily formed, implying that $\mathrm{Ti}_{2} \mathrm{Al}_{5}$ and $\mathrm{TiAl}_{2}$ phases can also be ruled out in this study. Finally, given the slower diffusivity of titanium atoms than aluminum atoms, thicknesses and phases of interface layers depend on the degree and distance of diffusion of aluminum atoms. In other words, compounds
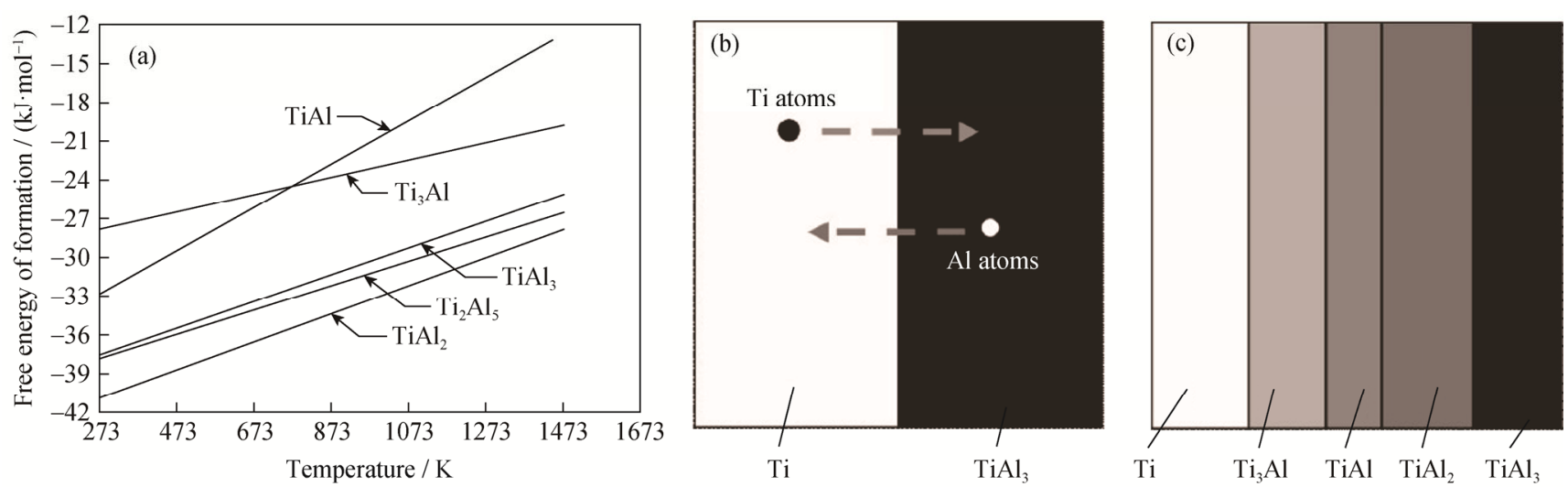

Fig. 7. Free energy-temperature spectrum line of $\mathrm{Ti}-\mathrm{Al}$ intermetallic compounds (a) and diffusion process between $\mathrm{Ti}^{2}$ and $\mathrm{TiAl}_{3}$ from 630 to $900^{\circ} \mathrm{C}(\mathrm{b}-\mathrm{c})$. 
present in reaction layers are determined by interdiffusion of aluminum atoms along grain boundaries, and this process is directly affected by interfacial heat content and element distribution [29]. From Refs. [30-31], $\mathrm{TiAl}_{2}$ and $\mathrm{Ti}_{2} \mathrm{Al}_{5}$ are mesophases of interfacial reactions and thus, they can also be ruled out considering thermodynamic effects.

\subsection{Strengthening mechanism on interfacial mechanical properties}

As mentioned earlier, cracks were only initiated in the $\mathrm{Al}$
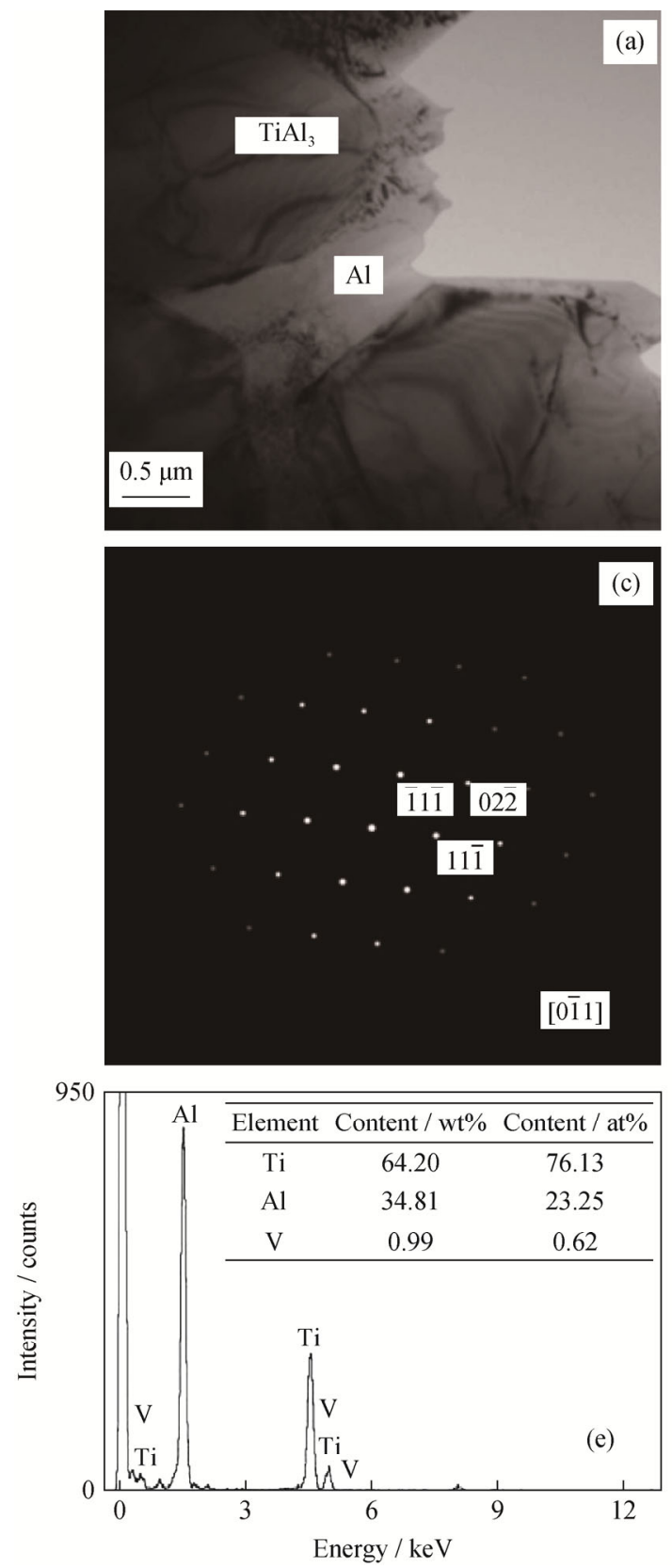

matrix for Ti-6Al-4V/Al7050 joints fabricated by insert molding. To further elucidate the strengthening mechanism on interfacial mechanical properties, HRTEM was used to examine interfacial microstructures. The HRTEM images of $\mathrm{Al} / \mathrm{TiAl}_{3}$ and $\mathrm{Ti} / \mathrm{TiAl}_{3}$ interfaces are illustrated in Figs. 8 and 9, respectively. EDS was used to characterize the elemental distribution. Based on HRTEM images, intermetallic compounds at the interface layer are evidently the $\mathrm{TiAl}_{3}$ phase and Al-alloy matrix, in accordance with Figs. 1 and 3, respectively. Indexed electron diffraction patterns indicate
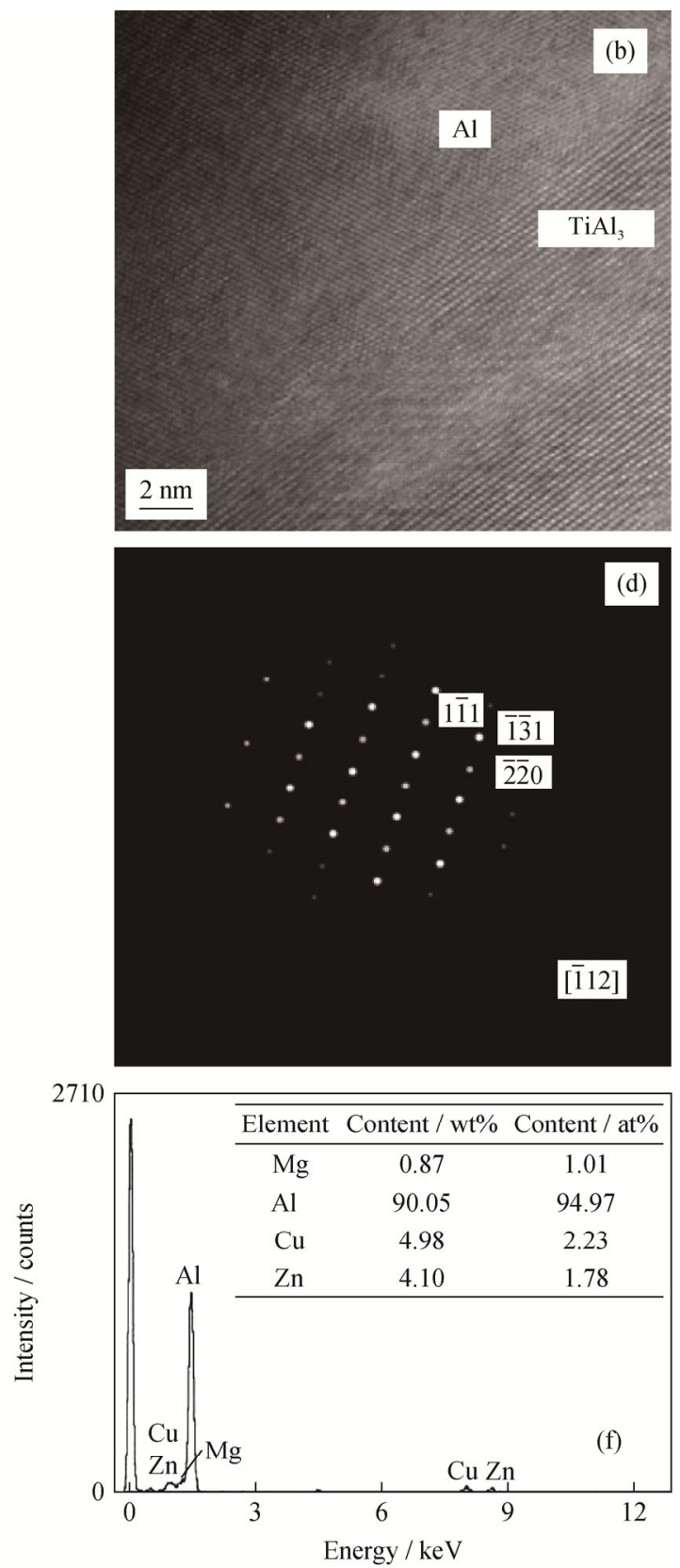

Fig. 8. TEM images, SADP, and EDS analyses of the Al/TiAl ${ }_{3}$ interface: (a) TEM morphology; (b) HRTEM morphology; (c) SADP of the Al phase shown in (b); (d) SADP of the $\mathrm{TiAl}_{3}$ phase shown in (b); (e) EDS spectrum of $\mathrm{TiAl}_{3}$ shown in (a); (f) EDS spectrum of Al shown in (a). 

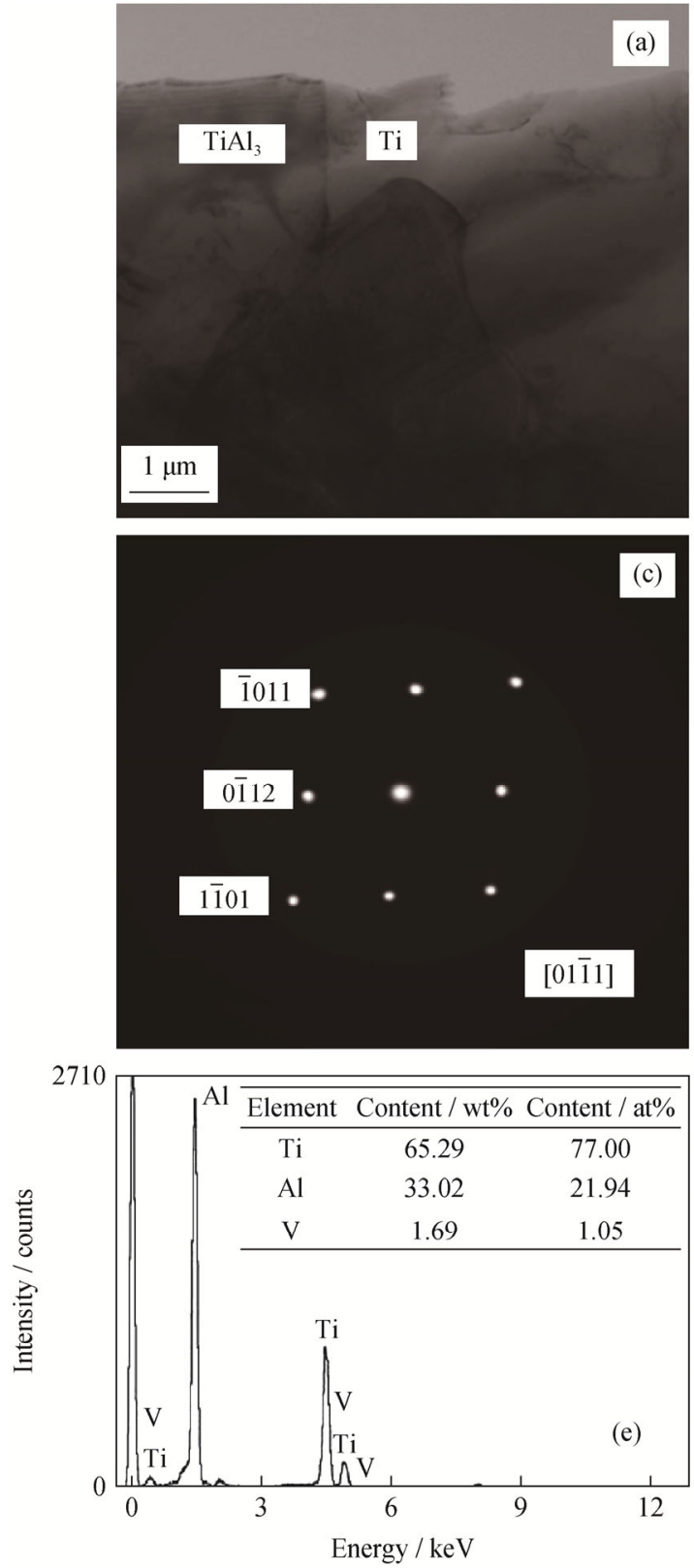
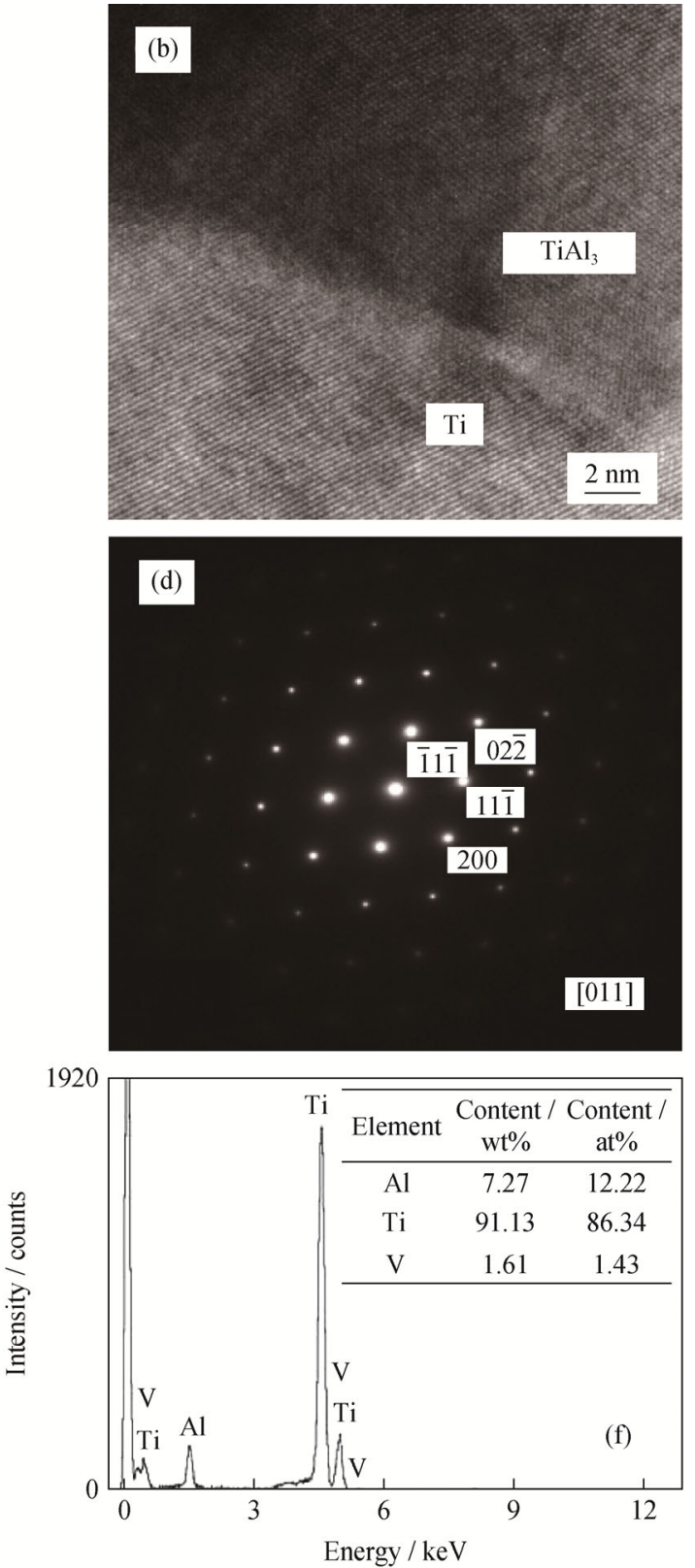

Fig. 9. TEM images, SADP, and EDS analyses of the Ti/TiAl ${ }_{3}$ interface: (a) TEM morphology; (b) HRTEM morphology; (c) SADP of the $\mathrm{TiAl}_{3}$ phase shown in (b); (d) SADP of the Ti phase shown in (b); (e) EDS spectrum of $\mathrm{TiAl}_{3}$ shown in (a); (f) EDS spectrum of Ti shown in (a).

the coherent boundary between $[0 \overline{1} 1]_{\mathrm{Al}}$ and $[\overline{1} 12]_{\mathrm{TiAl}_{3}}$ [23] and between $[011]_{\mathrm{TiAl}_{3}}$ and $[01 \overline{1} 1]_{\mathrm{Ti}}$. As a result of coherent $\mathrm{Al} / \mathrm{TiAl}_{3}$ and $\mathrm{TiAl}_{3} / \mathrm{Ti}$ boundaries, stress will concentrate at smaller casting flaws in the aluminum alloy matrix during deformation. This condition will explain why fracture constantly occurred in the Al matrix during tensile or compressive tests (Fig. 6). Therefore, to improve the mechanical performances of Ti-6Al-4V/Al7050 joints, mechanical performance of the aluminum alloy matrix should be enhanced through various strengthening methods, such as rolling and aging. Aside from $\mathrm{TiAl}_{3}$ intermetallic compounds, Ti particles (Fig. 4(c)), $\mathrm{S}\left(\mathrm{CuMgAl}_{2}\right)$, and $\mathrm{Al}_{3} \mathrm{Fe}$ phases (Table 2) were also present in the interface layer. However, their levels were very low at the interface, and they cannot influence the interfacial mechanical performance observed in this study.

\section{Conclusions}

In this study, Ti-6Al-4V/Al7050 joints with outstanding interfacial mechanical properties were successfully fabri- 
cated by the insert molding method. Conclusions can be summarized as follows:

(1) Good interfacial metallurgical bonding can be formed between two dissimilar alloys of Ti-6Al-4V and Al7050, ensuring high mechanical properties, i.e., shear strength of $154 \mathrm{MPa}$, tensile strength of $215 \mathrm{MPa}$, and compressive strength of $283 \mathrm{MPa}$.

(2) The corresponding interfacial bonding mechanisms were revealed. From thermodynamic analysis, phases formed at the interface of $\mathrm{Ti}-6 \mathrm{Al}-4 \mathrm{~V} / \mathrm{Al} 7050$ joints were mainly composed of $\mathrm{TiAl}_{3}$ and the $\mathrm{Al}$ matrix.

(3) Coherent $\mathrm{Al} / \mathrm{TiAl}_{3}$ and $\mathrm{TiAl}_{3} / \mathrm{Ti}$ boundaries were confirmed, explaining constant mechanical fracture in the $\mathrm{Al}$ matrix;

(4) Follow-up studies will focus on improving mechanical properties of the Al matrix by heat treatment and deformation.

\section{Acknowledgements}

This work was financially supported by the National Natural Science Foundation of China (Nos. 51671017 and 51471024) and Fundamental Research Funds for the Central Universities (No. FRFBR-15-078A).

Open Access This article is distributed under the terms of the Creative Commons Attribution 4.0 International License (http://creativecommons.org/licenses/by/4.0/), which permits unrestricted use, distribution, and reproduction in any medium, provided you give appropriate credit to the original author(s) and the source, provide a link to the Creative Commons license, and indicate if changes were made.

\section{References}

[1] Y.F. Han, W.D. Zeng, Y. Sun, and Y.Q. Zhao, Development of a database system for operational use in the selection of titanium alloys, Int. J. Miner. Metall. Mater., 18(2011), p. 444.

[2] X.F. Wang, M.X. Guo, L.Y. Cao, F.S. Wang, J.S. Zhang, and L.Z. Zhuang, Effect of rolling geometry on the mechanical properties, microstructure and recrystallization texture of Al-Mg-Si alloys, Int. J. Miner. Metall. Mater., 22(2015), No. 7, p. 738.

[3] Y. Jiang, C.P. Deng, Y.H. He, Y. Zhao, N.P. Xu, J. Zou, B.Y. Huang, and C.T. Liu, Reactive synthesis of microporous titanium-aluminide membranes, Mater. Lett., 63(2009), No. 1, p. 22.

[4] J. Oh, W. Lee, S.G. Pyo, W. Park, S. Lee, and N.J. Kim, Microstructural analysis of multilayered titanium aluminide sheets fabricated by hot rolling and heat treatment, Metall. Mater. Trans. A, 33(2002), No. 12, p. 3649.

[5] J.G. Luo and V.L. Acoff, Using cold roll bonding and annealing to process $\mathrm{Ti} / \mathrm{Al}$ multi-layered composites from elemental foils, Mater. Sci. Eng. A, 379(2004), No. 1-2, p. 164.

[6] S.H. Chen, L.Q. Li, Y.B. Chen, and J.H. Huang, Joining mechanism of Ti/Al dissimilar alloys during laser welding-brazing process, J. Alloys Compd., 509(2011), No. 3, p. 891.

[7] Y.B. Chen, S.H. Chen, and L.Q. Li, Influence of interfacial reaction layer morphologies on crack initiation and propagation in Ti/Al joint by laser welding-brazing, Mater. Des., 31(2010), No. 1, p. 227.

[8] Y.H. Chen, Q. Ni, and L.M. Ke, Interface characteristic of friction stir welding lap joints of Ti/Al dissimilar alloys, Trans. Nonferrous Met. Soc. China, 22(2012), No. 2, p. 299.

[9] H.S. Bang, H.S. Bang, H.J. Song, and S.M. Joo, Joint properties of dissimilar Al6061-T6 aluminum alloy/Ti-6\%Al-4\%V titanium alloy by gas tungsten arc welding assisted hybrid friction stir welding, Mater. Des., 51(2013), p. 544.

[10] M. Miki, T. Yamasaki, and Y. Ogino, Mechanical alloying of Ti-Al powder mixtures under nitrogen atmosphere, Mater. Trans. JIM, 34(1993), No. 10, p. 952.

[11] G.X. Wang, M. Dahms, G. Leitner, and S. Schultrich, Titanium aluminides from cold-extruded elemental powders with Al-contents of 25-75at\% Al, J. Mater. Sci., 29(1994), No. 7, p. 1847.

[12] K. Naplocha and K. Granat, Microwave activated combustion synthesis of porous Al-Ti structures for composite reinforcing, J. Alloys Compd., 486(2009), No. 1-2, p. 178.

[13] O. Dezellus, L. Milani, F. Bosselet, M. Sacerdote-Peronnet, D. Rouby, and J.C. Viala, Mechanical testing of titanium/aluminium-silicon interfaces by push-out, J. Mater. Sci., 43(2008), No. 6, p. 1749.

[14] O. Dezellus, M. Zhe, F. Bosselet, D. Rouby, and J. Viala, Mechanical testing of titanium/aluminium-silicon interface: Effect of T6 heat treatment, Mater. Sci. Eng. A, 528(2011), No. 6, p. 2795.

[15] X.Y. Nie, J.C. Liu, H.X. Li, Q. Du, J.S. Zhang, and L.Z. Zhuang, An investigation on bonding mechanism and mechanical properties of $\mathrm{Al} / \mathrm{Ti}$ compound materials prepared by insert molding, Mater. Des., 63(2014), p. 142.

[16] X.Y. Nie, K.N. Zhao, H.X. Li, Q. Du, J.S. Zhang, and L.Z. Zhuang, Comparisons of interface microstructure and mechanical behavior between Ti/Al and Ti-6Al-4V/Al bimetallic composites, China Foundry, 12(2015), No. 1, p. 1.

[17] M.S. Kenevisi and S.M. Mousavi Khoie, A study on the effect of bonding time on the properties of Al7075 to Ti-6Al-4V, Mater. Lett., 76(2012), p. 144.

[18] M.S. Kenevisi and S.M. Mousavi Khoie, An investigation on microstructure and mechanical properties of Al7075 to Ti-6Al-4V Transient Liquid Phase (TLP) bonded joint, $M a$ - 
ter. Des., 38(2012), p. 19.

[19] A.N. Alhazaa and T.I. Khan, Diffusion bonding of Al7075 to Ti-6Al-4V using $\mathrm{Cu}$ coatings and $\mathrm{Sn}-3.6 \mathrm{Ag}-1 \mathrm{Cu}$ interlayers, J. Alloys Compd., 494(2010), No. 1-2, p. 351.

[20] A. AlHazaa, T.I. Khan, and I. Haq, Transient liquid phase (TLP) bonding of Al7075 to Ti-6Al-4V alloy, Mater. Charact., 61(2010), No. 3, p. 312.

[21] M.S. Kenevisi, S.M. Mousavi, and M. Alaei, Microstructural evaluation and mechanical properties of the diffusion bonded Al/Ti alloys joint, Mech. Mater, 64(2013), p. 69.

[22] X.G. Chen, J.C. Yan, S.C. Ren, J.H. Wei, and Q. Wang, Microstructure and mechanical properties of Ti-6Al-4V/Al1060 joints by ultrasonic-assisted brazing in air, Mater. Lett., 95(2013), p. 197.

[23] M. Samavatian, A. Halvaee, A.A. Amadeh, and A.R. Khodabandeh, Transient liquid phase bonding of Al 2024 to Ti-6Al-4V alloy using $\mathrm{Cu}-\mathrm{Zn}$ interlayer, Trans. Nonferrous Met. Soc. China, 25(2015), p. 770.

[24] M. Samavatian, A. Halvaee, A.A. Amadeh, and A. Khodabandeh, An investigation on microstructure evolution and mechanical properties during liquid state diffusion bonding of Al2024 to Ti-6Al-4V, Mater. Charact., 98(2014), p. 113.

[25] M. Samavatian, A. Halvaee, A. Amadeh, and S. Zakipour,
Microstructure and mechanical properties of Al2024/Ti$6 \mathrm{Al}-4 \mathrm{~V}$ transient liquid phase bonded joint, J. Mater. Eng. Perform., 24(2015), No. 6, p. 2526.

[26] M. Ramiasa, J. Ralston, R. Fetzer, and R. Sedev, The influence of topography on dynamic wetting, Adv. Colloid Interface Sci., 206(2014), p. 275.

[27] N. Eustathopoulos, D. Chatain, and L. Coudurier, Wetting and interfacial chemistry in liquid metal-ceramic systems, Mater. Sci. Eng. A, 135(1991), p. 83.

[28] I. Ohnuma, Y. Fujita, H. Mitsui, K. Ishikawa, R. Kainuma, and $\mathrm{K}$. Ishida, Phase equilibria in the Ti-Al binary system, Acta Mater. 48(2000), No. 12, p. 3113.

[29] F.J.J. Van Loo and G.D. Rieck, Diffusion in the titanium-aluminium system-I. Interdiffusion between solid Al and Ti or Ti-Al alloys, Acta Metall., 21(1973), No. 1, p. 61.

[30] M. Sujata, S. Bhargava, and S. Sangal, On the formation of $\mathrm{TiAl}_{3}$ during reaction between solid Ti and liquid $\mathrm{Al}, J$. Mater. Sci. Lett., 16(1997), No. 3, p. 1175.

[31] U.R. Kattner, J.C. Lin, and Y.A. Chang, Thermodynamic assessment and calculation of the Ti-Al system, Metall. Trans. A, 23(1992), No. 8, p. 2081.

[32] H. Okamoto, Al-Ti (aluminum-titanium), J. Phase Equilib., 14(1993), No. 1, p. 120. 